\title{
A Study on the Combination of 3 D Printing Technology and Computer Aided Industrial Design
}

\author{
Shi Yichun \\ Department of Information Engineering, Jiangsu Union Technical Institute, Nanjing, Jiangsu, 210000, China \\ email: 75191182@qq.com
}

Keywords: 3D Printing Technology, Computer, Industry, Design

\begin{abstract}
With the advancement and development of industrialization process in our country, seeking more convenient and effective way of industrial design has become the most important part of today's society. $3 \mathrm{D}$ printing technology, as an important part of advancing industrial design, can improve the efficiency of production on the one hand, but also better understand the design characteristics of an industrial region on the other. Based on the analysis of 3D printing technology and computer aided industrial design, this paper hopes to promote the better integration between the two and promote the continuous efficient, healthy and continuous development of industrial design in China.
\end{abstract}

\section{The Connotation of Computer Aided Industrial Design}

With the rapid development of the national economy and the advancement of the process of industrialization in the world, industrial design also emerged as the times require. At first, for most cases of industrial design only exist in the shape of products, decoration and other simple fields; with the continuous development of industrialization, to this day, not only the concept of industrial design has changed, the field of design has been expanded accordingly. With the application of 3D printing technology to industrial design, it not only effectively reduces the production cycle of industrial products, but also promotes the prosperity and development of market economy.

Computer aided industrial design means industrial design through computer technology. Compared with traditional industrial design, it is not only convenient, simple and easy to see, but also can design better industrial schemes [1]. In the era of big data, the use of computer-aided industrial design can shorten the design time and leave more sufficient time for subsequent work. At the same time, with the help of computer-aided industrial design, we can get the design scheme quickly, and design a more reasonable scheme according to the market trend.

\section{3D Printing Technology}

3D printing technology is based on digital models, using powder metal or plastic, etc., by layerby-layer printing to construct the object technology. A 3D printer can be more vividly designed than a common printer in everyday life (Figure 1).

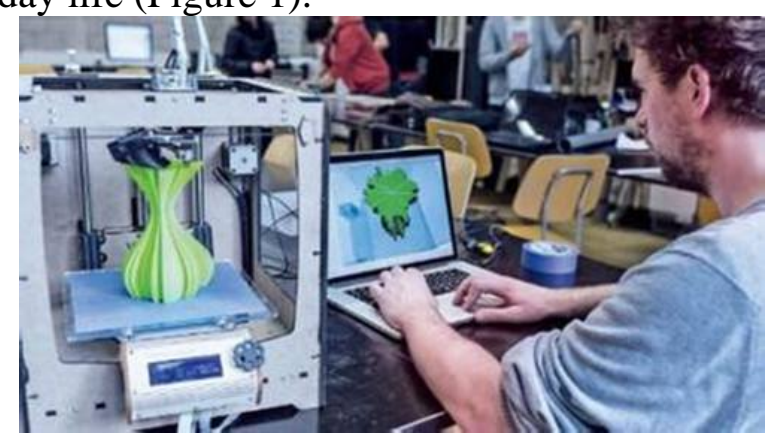

Figure 13 D Printing technology

To help people better analyze, understand the significance of design and the need for 
improvement, make industrial design more humane, more in line with the requirements of the modern market.

\section{Relationship between 3D Printing Technology and Computer Aided Industrial Design}

3D printing technology and computer, the two are independent individuals, but also the relationship between each other, in the actual industrialization, computer-aided industrial design can provide more accurate digital $3 \mathrm{D}$ printing technology, and then ,3D printing technology based on the data obtained in the computer to transform the design scheme into physical objects, the two work together to improve the design speed of industrial products, but also improve the quality of product design.[2]. In addition, the two complement each other, the joint action can shorten the industrial time, is the product to put into the market more quickly, enhances the product market share.

\section{Advantages of 3D Printing Technology in Computer Aided Industrial Design}

The use of 3D printers and computer-aided design in industrial design is not only helpful for designers to change their traditional design methods and escape from the inherent design concept, but also to get rid of the original restrictions of creating and designing conditions, and to better design products according to their own ideas. It can not only stimulate designers' enthusiasm for design, but also increase the charm of products.

Design work technology, so that ideas, design, production and service concept into one, share a data platform, real-time grasp of the views of different groups of people, to achieve design and production more to meet people's needs; improve the value of design and manufacturing, compared to the traditional production of the product surface too rough, product appearance simulation and other problems,

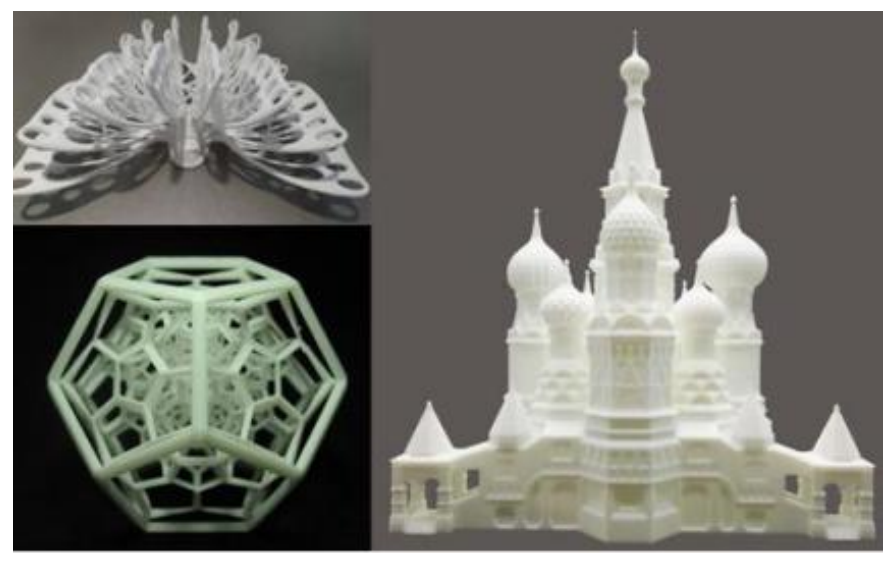

Figure 2 3D Print

$3 \mathrm{D}$ printing technology is competent for the work of the craftsmen (Fig .2), which makes the model more rational and practical through precision design, careful grinding, leak-filling [3]. 3D printing technology can provide manufacturing samples, shorten the time to draw drawings, convert conceptual design into 3D model within a few days to meet people's visual requirements. At the same time, for the problems existing in the process, the modification can be completed in the computer operation, so as to make rapid evaluation, modification and function test of the products in the design stage, which can greatly reduce the cycle trial production and production cost, and increase the competitiveness and market share of the products. And with the development of 3D printing technology, the number of prototype materials that can be used in manufacturing is increasing, and the properties are also greatly improved compared with the past. Some of the raw materials, such as non-metal with good mechanical strength and thermal stability, can be directly put into the manufacturing of the model and greatly shorten the industrial cycle. 


\section{Impact of 3D Printers and Computer Aided Design on Industrial Design}

Design by the designer, the number of consumers influence the value of the design and gold content. With the development of social economy, consumers directly influence economic development. Because consumers are different individuals, the demand tends to be diversified, individualized and differentiated. The diversity of these trends is reflected not only in the daily shopping, but also in the decoration and aesthetics of the family [4]. Using 3D printer, on the one hand, designers can fully "fly" their own imagination, and then according to their own ideas to design a novel scheme, and then modify, improve, make the drawings more humane. The "virtual world" provided by 3D printers can not only stimulate the imagination space of design and the desire to create, but also help to provide consumers with more abundant products, and then improve the popularity of products. In the long run ,3D printing technology can make designers maintain long-term design enthusiasm, not only can effectively improve the designer's design ability, but also effectively improve the designer's aesthetic ability (Fig .3).

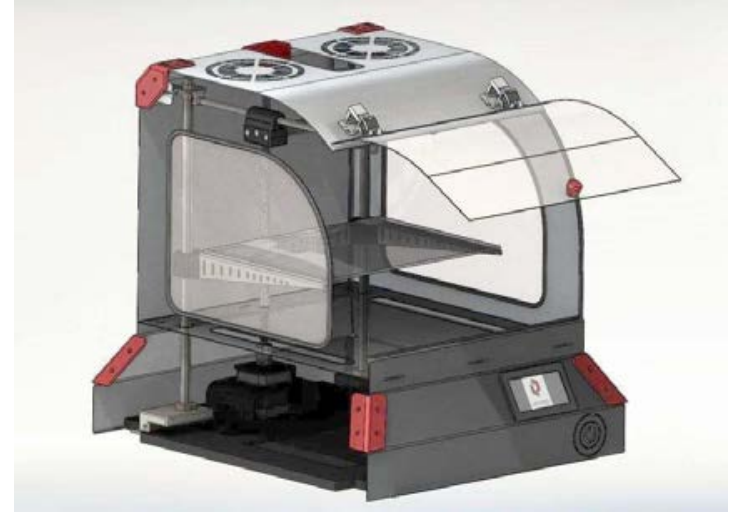

Figure 33 D Printer

3D printing application redesign of various fields, effectively improve the efficiency of production. In industrial design, designers and model builders can use 3D printer technology to turn the design scheme into a physical object, and then show the model to the customer and the whole design team, and then extract the customer's opinions, and reflect the customer's suggestions in the product design, so as to build a good communication bridge for the designer and the customer. By communicating with customers and listening to customer opinions, we can adjust the design scheme in time and effectively, so that the products can flow into the market better and faster, and get the recognition of the market and consumers in a short time, optimize the design resources and increase the market share.

In addition, the use of 3D printing technology for design, the designer has a great impact. For example, designers can turn their ideas into real things according to 3D printing technology, not only appear a large number of independent designer design brand, but also break the original design structure, but also more meet the individual differences of consumers.

Finally, with the continuous innovation of technology, the technical ability of $3 \mathrm{~d}$ printer is also increasing, consumers are no longer pure recipients, they can also use 3d printer to design the products they want, and become a veritable "designer ". The most important thing is that most products can be marked as the personalized needs of consumers, in the process only need merchants to provide consumers with a production platform, consumers can design their products according to their own preferences. Just as things have been changing and moving, the consumer's demand for the product has changed over time and the impact of mainstream values, and through the consumer's own design, the product will become unique.

\section{Development of 3D Printing Technology and Computer Aided Industrial Design in the Future}

With the development of Internet technology, the emergence and innovation of artificial intelligence and the development of computer intelligence, designers and every consumer can use 
computer-aided design to complete the model of things they want, and use 3D printer to concretize abstract things. But using computer-aided design requires every designer and consumer to master the professional operation process, and needs the designer to show his own design idea more intuitively and acutely, need the consumer to understand the essence of design better, so as to carry on the product design better. At the same time, with the country's emphasis on education and the promotion and improvement of educational reform ,3D printing technology will enter the school in the future one day, into the teacher's classroom, can not only become the teacher's favorable teaching assistant, but also can make the complex and abstract problems concrete, vividly show in front of the students, provide good learning classroom to the god of learning, create a good learning atmosphere, so as to continuously promote the progress of teaching and the development of students' comprehensive quality. Finally, with the improvement of people's living standards, people's demand for new things will increase day by day, and computer-aided design is bound to go to the family, let the family through their own ideas and ideas to create their own home characteristics of decoration, architectural style, not only to promote family harmony, but also to redesign the process of better understanding of family members, promote family harmony, promote the socialist family harmony, respect the old and love the young values.

In a word, with the technological reform and the needs of people's life ,3D printing technology and computer-aided design will eventually go through innovation and reform, and then provide a more convenient operation process for the society for designers and consumers.

\section{Conclusion}

3 D printing technology and computer-aided industrial design are also a form of information technology. The combination of the two can effectively improve work efficiency and greatly shorten the period of product flow into the market. Designers can use the $3 \mathrm{D}$ printing machine to release imagination space to design richer product styles to meet the individual needs of consumers; At the same time, using $3 \mathrm{D}$ printing technology and computer-aided industrial design can not only better adapt to the socialist market economy, but also take the lead to seize the market, increase consumers, improve product reputation, promote the healthy and sustainable development of industry, and make it survive in the increasingly competitive socialist market economy for a long time.

\section{References}

[1] Hao Jianfeng. Computer aided industrial design and 3D printing technology. Light Industry Technology, no. 8, pp. 71-72, 2016.

[2] Ma Ruichen. Computer aided industrial design and 3D printing technology. Electronic Technology and Software Engineering, no. 23, pp. 155-155, 2016.

[3] Duan Wei. Computer aided industrial design and 3D printing technology. Intelligence, no. 12, pp. 233, 2019.

[4] Yin Guanghui, Chen Hang, You Jun, et al. 3D printing technology in industrial design. Science and Education Journal (Chinese Journal), vol. 335, no. 04, pp. 62-64+67, 2018. 